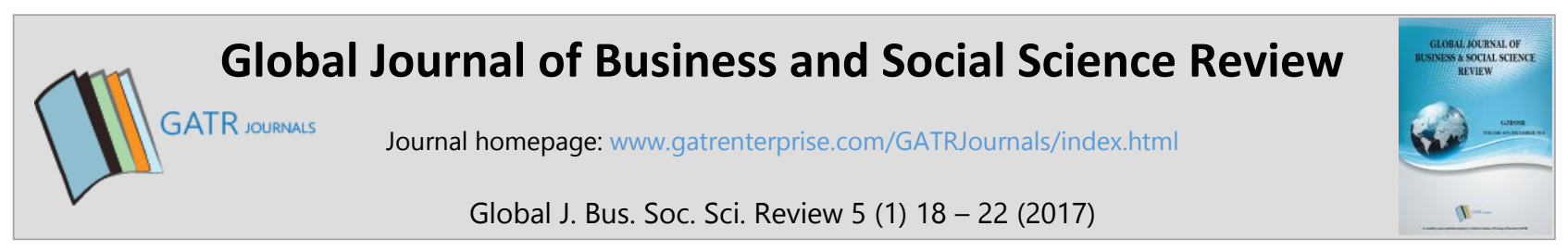

\title{
Classroom Arrangement through Computer: A New Approach
}

\author{
Irshad Ullah ${ }^{1 *}$ and Aamna Irshad ${ }^{2}$ \\ ${ }^{1}$ Education Department, Government of Khyber Pakhtunkhwa, 44000, Islamabad, Pakistan \\ ${ }^{2}$ Centre for Counseling and Career Advisory, National University of Sciences and Technology, 44000, Islamabad, Pakistan
}

\begin{abstract}
Objective - In the classroom, computers can be used for its better learning arrangements. Computers can be used either by the teacher or the learner but whatever way it is used, it is an important tool in the teaching-learning environment. Without proper class room arrangement and management, it becomes difficult to create a proper environment for learning. It can also affect the learning behaviors of students. Student may learn more effectively and efficiently in a cool environment. Different educationalists from the education field put in a lot of effort in this respect, suggesting many different methods for solving learning problems. In this paper an attempt has been made to demonstrate how computers may assist in the arrangement of classes for better learning environments.

Methodology/Technique - Different perspectives are investigated by collecting data from both students and teachers with different levels of familiarity with the use of computers in the learning environment.

Findings - Based on the analysed results, different techniques and strategies are proposed for use in the classroom to achieve better learning environments.
\end{abstract}

Novelty - The study suggests an approach for classroom arrangement though the use of computers.

Type of Paper: Empirical.

Keywords: Computer; Internet; Management; Students; Class.

JEL Classification: I21, O32.

\section{Introduction}

Class room management is used as a process by the teacher to ensure that the class room study environment runs smoothly, even where the behavior of some students may disturb the class. Class management tools are also used to prevent these kinds of student disturbance; this is one of the hardest things to learn as a teacher. In 1981, the United States Association of the National Education estimated that $36 \%$ of the teaching staff surveyed suggested that if they were given a second chance to choose their career, they would not choose teaching a second time. This was predominantly due to the misbehaviour of students (Charles \& Carl, 1986). Moskowitz and Hayman believe that when a teacher loses control of their classroom, it becomes very difficult for them to regain that control (Moskowitz \& Hayman, 1976). Research has also demonstrated that poor

\footnotetext{
* Paper Info: Revised: September, 2016

Accepted: January, 2017

* Corresponding author:

E-mail: irshadullah79@gmail.com

Affiliation: Education Department, Government of Khyber Pakhtunkhwa, Pakistan
} 
classroom management almost always results in poor academic performance and student engagement in the academic environment (Berliner, 1988).

Good classroom organizers keep a tight control of their classroom from the first day of class. They also organizers the classroom activities according to the needs of their students. They enquire about the aim of learning processes and outcomes, teaching methods, examination procedures and ways to achieve maximum success. They want to know about the coming days activities. Keeping in mind all of these things, propose that a middle school teacher arranges and organizes their opening days' activities. The school teacher has to organize the goals of that day, the method of instruction to the students, the assessment scheme and how the students will be dealt with after the examination. The teacher must tell the student about the best learning method and must demonstrate to the students the best method of success. They must give an insight into the next session and they must also inform students of the availability of resources to complete the given tasks. A school teacher has to arrange these activities effectivel and must be able to keep the class room environment smooth and calm (Brooks, 1985).

The ability to manage a class effectively is very closely related to motivatation, discipline and respect. To achieve the goals of the classroom, the methods are different depending on the way each teacher was taught to teach a classroom. Traditionally, classroom management involves being forceful on behavioral modifications although some of the teachers think that these are basic skills possessed by all students. Many teachers define standards of behaviour by students in the beginning of the new school year. As Gootman says, that to describe and define the rules gives the students expectations on how to achieve their goals and objectives (Marilyn, 2008). Teachers are always trying to maintain consistency in the way they enforce these rules and regulations in the classroom. They also have to remember to give a positive reinforcement when the rules are followed.

Holistic approaches are another way of managing a classroom. For example, a teacher attempts to create an environment in which students make their own efforts and as a result of these efforts, students get the credit for success. Such techniques are dependent on the students use of self learning initiatives (Pintrich \& Groot, 1990). Such techniques are very good for the management of a classroom and in such an environment.

From the literature above it is clear that classroom arrangement is not a simple task. Different education experts and the studies above give different suggestions as to how to cope with this difficulty. Some researchers believe that it is motivation and discipline which will effect the learning environment. They propose different methods for it as given in the next section one by one in detail.

\section{Methods}

\subsection{Corporal Punishment}

For control of a class, corporal punishment is widely used by some organizers. However, despite being legal in some schools, most of the community frown upon such punishment.

\subsection{Rote Discipline}

This method is also known as "lines," and uses negative sanction to manage the classroom environment. In this approach, students are assigned rules to write again and again.

\subsection{Preventative Techniques}

In these approaches a community of self respect among teachers and the students is developed. Here, teachers use the preventive techniques, offering love and support without any condition whilst transparent rules and penalties are established. The students are given very fair and consistent feedback about their attitude and behavior (Bear, 2008). This may be obtained by a classroom agreement and this technique has to be created by both student and teachers. They must decide that how to deal with each other in the classroom. They must clearly decide what will be the punishment if there is violation of the agreement from any of the parties, 
whether this agreement be reached through group discussion, peer negotiation, or with the discussion of the method one on one. The method must lead to the solution of the problem. These methods also involve giving rewards and prizes to the students for good behaviour but the teacher must define what good behaviour is and on what basis a student will receive a reward (Bear et al., 2005).

\subsection{The high-quality Behavior Game}

In this approach a reward is given for good behavior and then taken away for undesired behavior. This approach may be used with pre-schoolers and also their elders however it is usually used for developing students (Tingstrom et al., 2006).

\subsection{Organized Approaches}

CRCM (Culturally Responsive Class Room Management) is an approach involving setting up classrooms with students who all possess the same behavioural problems, so as to implement the same rules and procedures for every student in that class.

\subsection{Regulation with no Stress, Punishments/Rewards}

The students who obey rules and regulations most likely do not affect the teachers ability to manage the classroom. In this approach the young people are preparing for an environment where they know about the values and norms. They will be responsible for themselves and must maintain a self-disciplined society. This method produces a motivation in the young to achieve a high level of self-discipline (Marvin, M. 2001).

\subsection{General Mistakes in Classroom Organization}

To maintain good classroom management, it is necessary to keep an eye on the entire situation because the situation may become worse without the teacher knowing as a result of not defining what constitutes problem behavior (Charles, 1968). In addition, in some situations where two or more students misbehave, they may need to be punished differently. It must be understood that not every type of behaviour management strategy used by teachers will be effective for every child. Teachers must be flexible in order to effectively manage the classroom and they must be willing to take alternative measures to achieve the desired results (Charles, 1968). To make an approach workable, the teacher must work for it. Teachers must also be consistent with their approaches to ensure classroom management by guiding and telling the student that rules must be followed and obeyed. The student has to be convinced that the rules are for their betterment of the class so that they do not ignore the rules. In this respect, approval of good behaviour is a good technique for classroom management. In the same way, it is important for teachers to give students opportunities to correct their behaviour when needed, rather than punishing them for even insignificant deviations from the established norm. 


\section{Results}

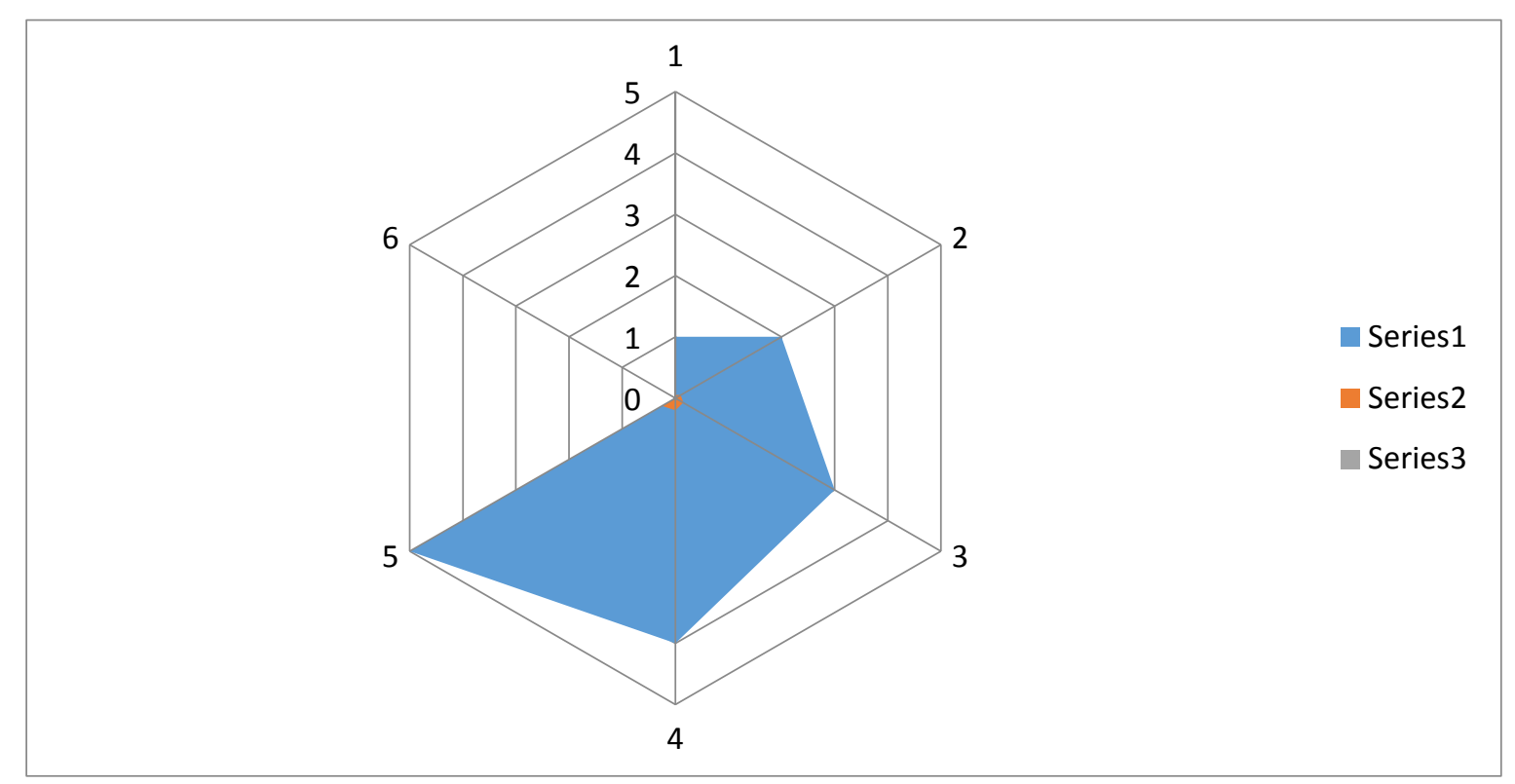

Figure 1: Result Analysis

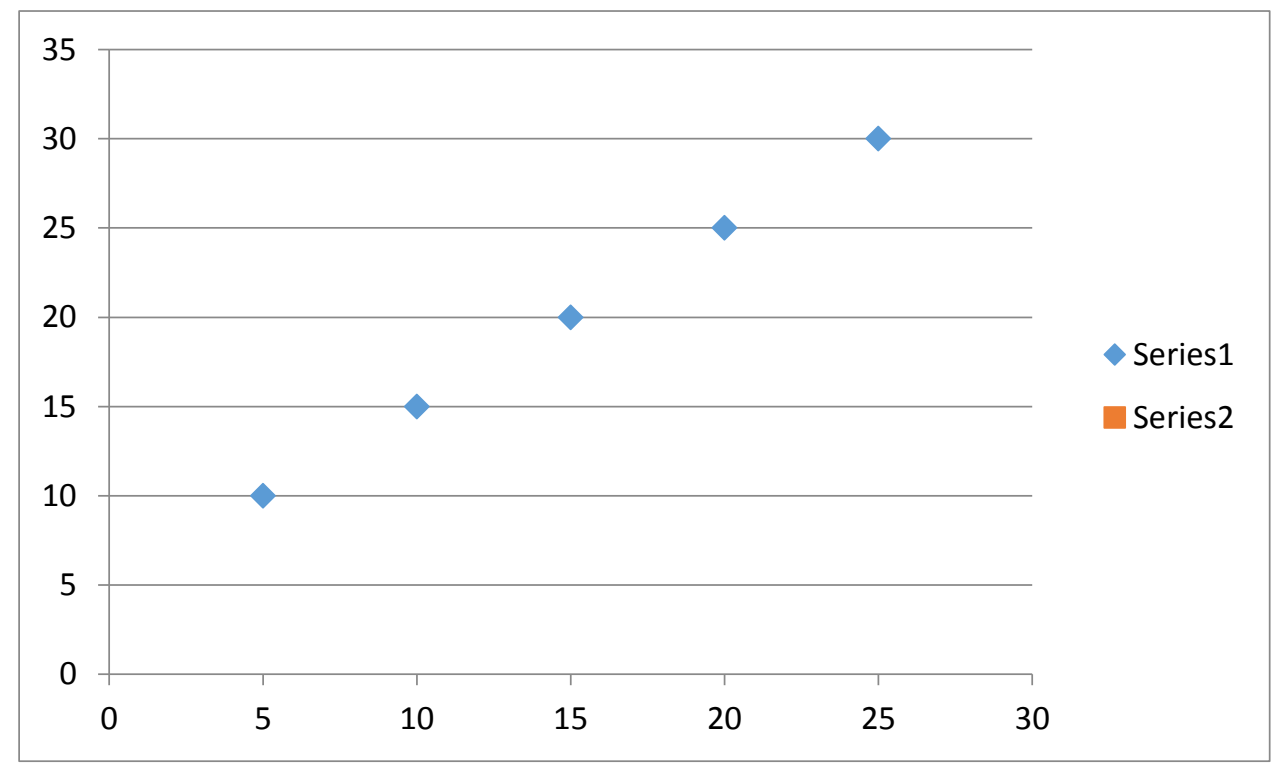

Figure 2: Result Analysis

\section{Discussion}

The methods of data collection used were observation, interview and questionnaire. Both structured and unstructured interview methods were used to collect the data. From the results, it is observed that computers can help with classroom management. Students can use computers to learn by using it for different classroom tasks like thesis writing, assignment preparation etc. It also helps teachers deliver and prepare for lectures by using the Internet and programs such as Microsoft Power Point. The results also show that rewarding good behaviour and ignoring smaller behavioural inconsistencies by students who are usually well behaved can 
improve the students' performance and the overall classroom environment. Diverse techniques are required to make the classroom environment more efficient and consistent.

\section{Conclusion}

From the results it is clear that computers may help both teachers and students thus assisting classroom management in a new and modern way. It has been shown that by applying different techniques, effective classroom management can be achieved. The results also show that teachers must be versatile in their nature and their techniques. The techniques must be flexible to adopt and treat different students differently according to their nature.

In future this research may be extended to provide further clarification of the results. Sample sizes may also be increased according to the situation. A lot of research can be performed as it is a very broad area to work. More research may be conducted on how to make classroom management techniques more flexible with the aim of making classroom arrangements act like a community. Also teachers may be given more technique options to make the community more self-responsible.

\section{References}

Bear, G. G. (2008). Best Practices in Classroom Discipline. Best Practices in School Psychology, National Association of School Psychologists.

Bear, G. G., Cavalier, A. and Manning, M. (2005). Developing Self-discipline and Preventing and Correcting Misbehaviour. Boston: Allyn \& Bacon.

Berliner, D. C. (1988). Effective Classroom Management and Instruction: A Knowledge base for Consultation, Handbook of Research on Teaching. (3rd ed., pp. 328-375). New York: Macmillan.

Brooks, D. M. (1985). The First Day of School. Educational Leadership, 42(8), 76-78

Charles, M. (1968). Rules, Praise and Ignoring: Elements of Elementary Classroom Control. Applied Behavior Analysis

Charles, W. H. and Carl, G. D. (1986). Solving Discipline Problems. Allyn and Bacon. ISBN 0205086306.

Culturally Responsive Classroom Management Strategies. Metropolitan Centre for Urban Education. Retrieved from www.steinhardt.nyu.edu/metrocenter.

Marilyn, G. E. (2008). The Caring Teacher's Guide to Discipline: Helping Students Learn Self-control, Responsibility and Respect, K-6. p. 36. ISBN 1412962846.

Marvin, M. (2001). Discipline without Stress, Punishments or Rewards. Los Alamitos: Piper Press. ISBN 0-9700606-10 .

Moskowitz, G. \& Hayman, J. L. (1976). Success Strategies of Inner-city Teachers: A Year-long Study. Journal of Educational Research 69(8): 283-289.

Pintrich, P. R. \& Groot, E. V. (1990). Motivational and Self-regulated Learning Components of Classroom Academic Performance. Journal of Educational Psychology, 82, 33-40.

Tingstrom, D. H., Sterling-Turner, H. E. \& Wilczynski, S. M. (2006). The Good Behavior Game. Behavior Modification, 30 (2), 225-253. 